Purdue University

Purdue e-Pubs

Purdue CIBER Working Papers

Krannert Graduate School of Management

$1-1-1993$

\title{
Industry and Country Effects on Manager's Perceptions of Environmental Uncertainties
}

Kent D. Miller

Purdue University

Follow this and additional works at: http:// docs.lib.purdue.edu/ciberwp

Miller, Kent D., "Industry and Country Effects on Manager's Perceptions of Environmental Uncertainties" (1993). Purdue CIBER Working Papers. Paper 72.

http://docs.lib.purdue.edu/ciberwp/72

This document has been made available through Purdue e-Pubs, a service of the Purdue University Libraries. Please contact epubs@purdue.edu for additional information. 


\title{
INDUSTRY AND COUNTRY EFFECTS ON MANAGER'S PERCEPTIONS OF ENVIIRONMENTAL UNCERTAINTIES
}

\author{
Kent D. Miller
}

93-105

Center for International Business Education and Research Purdue University Krannert Graduate School of Management 1310 Krannert Building

West Lafayette, IN $47907-1310$

Phone: (317) 494-4463

Fax: (317) 494-9658 


\section{INDUSTRY AND COONTRY EFFECTS ON MANAGERS' PERCEPTIONS}

OF ENVIRONMENTAL UNCERTAINTIES

Kent D. Miller

May 11, 1993

Krannert Graduate School of Management

Purdue University

1310 Krannert Building

West Lafayette, IN 47907-1310

(317) 494-5903

BITNET: kmiller@purccvm.bitnet

The author wishes to thank Joyce Osland and INCAE for facilitating data collection. Philip Bromiley provided helpful comments on an earlier draft. Funding from the Midwest Universities Consortium for International Activities, Inc. (MUCIA) and the University of Minnesota Graduate School is gratefully acknowledged. 


\section{INDUSTRY AND COUNTRY ERFECTS ON MANAGERS' PERCEPTIONS \\ OP ENVIRONMENTAL UNCERTAINTIES}

International management research highlights political, government policy, and macroeconomic uncertainties. Strategy studies focus on input supply, product market, and competitive uncertainties. This study develops and tests the reliability of an instrument for measuring managers' uncertainty perceptions. Data analyses using an international sample provide insights into the relative importance of country and industry factors for explaining managers' perceptions of different environmental uncertainties. 
Managers operating in the international business context confront a variety of uncertain environmental factors. In the past, international risk management researchers have focused primarily on the assessment of political. government policy, and macroeconomic (particularly foreign exchange) uncertainties and appropriate organizational responses. This emphasis differs markedly from the risk management discussions found in the strategy field, where researchers view industry dynamics as giving rise to managerial uncertainties. As such, the strategy field emphasizes uncertainties regarding product and process technologies, the availability of critical inputs, product market demand, and strategic moves by competitors and potential entrants.

Political, government policy, and macroeconomic uncertainties reflect international management researchers' interest in the country level of analysis. By contrast, much of the strategy literature, particularly that grounded in industrial organization economics, sees industry', rather than country, as the relevant level of analysis for risk assessment. Porter's (1985) discussion of competitive strategy under uncertainty exemplifies the industry-oriented risk management perspective. While recent strategy research reflects a growing interest in integrating strategy and international management perspectives (see, e.g., Porter, 1990), such integration is not yet evident in most risk management research.

The disparity between international management and strategy emphases on country and industry levels of analysis for risk assessment presents an important empirical question: do country, industry, or a combination of both determine the uncertainties managers perceive? This question, motivated by the disparities between previous strategy and international risk management research; has practical relevance to managerial decisions regarding product and international market diversification. If, for example, uncertainties differ systematically across industries but not across countries, then assessing the particular country context is irrelevant to determining corporate risk exposure. Alternatively, if uncertainties differ across countries, international diversification may reduce the variability of corporate performance beyond the risk reduction achieved through product diversification. 
This paper makes two primary contributions to the existing management research on uncertainty. First, the research develops and tests a perceived environmental uncertainty measurement instrument grounded in strategy and international management theory. We are not aware of any previous research which has developed and tested measures of perceived environmental uncertainty differentiating the managerially relevant uncertainties of interest to strategy and international management researchers. Second, the study tests the relevance of country and industry effects on managers' perceptions of environmental uncertainties.

The opening section of this study provides theoretical background on country and industry effects on uncertainties and motivates testable hypotheses. The following section discusses the problems with existing uncertainty measurement instruments and proposes an alternative approach. The empirical section begins with a description of the sample. The unique data collected for this research consisted of responses from nearly five hundred managers in 211 firms in six Latin American countries. The empirical section examines the reliability of the perceived uncertainty instrument developed in this research. Next, data analyses provide insights into the relative importance of country and industry factors for explaining managers' perceptions of environmental uncertainties. The final portion of the paper discusses the empirical findings and their implications.

\section{BACKGROUND AND HYPOTHESES}

"Uncertainty" refers to the unpredictability of environmental or organizational variables that impact corporate performance. A conceptual shortcoming in much of the existing literature on uncertainty is the tendency to isolate particular managerial uncertainties to the exclusion of others. For example, international risk management research has produced streams of research on political and foreign exchange uncertainties. Strategy researchers have examined factor and product market, technological, and competitive uncertainties. Little research integrates these various perspectives on organizational uncertainties.

Miller (1992) proposed a threefold categorization of managerial 
uncertainties. Managers may perceive as uncertain (1) general environmental. (2) industry, and (3) firm-specific variables. General environmental uncertainties include political and government policy instability, and macroeconomic uncertainty. Industry uncertainties encompass input market, product market, competitive, and technological uncertainties. The third category, firm-specific uncertainties, includes uncertainties regarding operations, research and development, and management and employee actions. Assessing these various uncertainties is relevant to formulating organizational strategic and financial risk management responses. For example, firms often purchase financial market hedging instruments (such as forward or futures contracts and options) to reduce exposures to unexpected movements in commodity prices, interest rates, and foreign exchange rates. In the absence of market instruments to hedge exposures to uncertainties, firms may make real changes in strategies to reduce risk. One such case occurs when firms seek to establish joint ventures for new product development in response to technological uncertainty. Another case is backward vertical integration to reduce input uncertainty. Many other examples could be cited illustrating the managerial relevance of differentiating environmental uncertainties. In order to assess the uncertainties of interest to managers, it would be quite useful to know the extent to which uncertainties generalize across business firms. Knowing if uncertainties differ systematically across countries and/or industries would provide an indication to managers of the relevant level of analysis for assessing corporate risk exposures.

Previous international risk research raised the issue of the relevant level of analysis for assessing risks. Robock (1971), Kobrin (1982), and Simon (1982) distinguished between political microrisks and macrorisks. Macrorisks impact the full spectrum of business firms in a country. Microrisks affect certain business activities exclusively. Drawing on the macrorisk/microrisk distinction, both Ting (1988) and Lessard (1988) observe that many risks are peculiar to specific corporate investments.

The starting point for this study was the hypothesis that managers' perceptions of environmental uncertainties differ across countries and industries in a manner consistent with the levels of analysis indicated in the 
Miller (1992) typology of uncertainties. That is, political, government policy, and macroeconomic uncertainties were expected to differ across countries but not across industries. Political uncertainty refers to the unpredictability of changes in political regimes (Shubik, 1983; Ting, 1988). Policy uncertainty, on the other hand, indicates instability in government policies that impact the business community (Ting, 1988). Both political and policy changes are subject to national social influences and sovereign choice, and, as such, should differ from one country to another. Macroeconomic uncertainty encompasses fluctuations in the level of economic activity and prices. To the extent that national product and financial markets are segmented, managers operating in different countries should experience distinct levels of macroeconomic uncertainty.

Previous discussions in the international management field generally assumed differentiation of political, policy, and macroeconomic uncertainties at the country level but have not examined whether this assumption is consistent with managers' perceptions. The assumed relevance of country analyses underlies the existence of professional country risk assessment services. This paper tests the legitimacy of that assumption. The specific hypothesis is:

\section{1: Polltical, government pollcy, and macroeconomic uncertainties differ across countries but not across industries.}

Several arguments raise questions about the validity of this hypothesis. First, consider some reasons why national distinctions may be irrelevant to managers' perceptions of general environmental uncertainties. One possibility is that there are limited objective political, policy, and macroeconomic differences across countries. In many regions of the world, political, policy, and macroeconomic instability spill over from one country to another. Alternatively, international collaboration on political and economic policy have the potential to homogenize general environmental conditions across countries. In economically integrated regions, countries may be undifferentiated in their levels of macroeconomic uncertainty. 
Even if objective differences exist in political, policy, and macroeconomic stability, managers' characterizations of their countries may not reflect these differences. Managers may characterize current uncertainties with respect to their own past experience (Tversky \& Kahneman, 1973). If so, managers' perceptions would not share a common reference point across countries for making cross-sectional international comparisons. Managers also appear to have different tolerances for ambiguity across countries (Hofstede, 1980) which may exaggerate or diminish perceived uncertainty differentials across countries relative to some "objective" measure of environmental instability.

A second alternative to the hypothesis (HI) is that industry effects are actually significant in explaining the perceived uncertainty of political, policy, and macroeconomic environmental components. This could be due, for example, to differential effects of political change or government policy decisions across industries, making political and policy uncertainty much more salient in certain industries than in others. Certain industries may be more severely impacted by unpredictable macroeconomic fluctuations (e.g., cyclical or interest rate sensitive industries). If these conditions hold, industry effects could be found to be significant in determining political, policy, and macroeconomic uncertainties.

Uncertainties regarding inputs used by the firm, competition, and product market demand should vary across industries. Input market uncertainty refers to unpredictability in the acquisition of adequate quantities and qualities of production inputs. Product market uncertainty results from unpredictable changes in product demand. Competitive uncertainty covers the uncertainties regarding strategic moves by existing firms and potential entrants into an industry.

The relevance of industry analyses in assessing these managerial uncertainties is a basic contention of risk management discussions in the strategy field. The three categories of industry-level uncertainties correspond with Porter's (1980) widely cited five forces of industry competition. Input and supply uncertainty coincide with distinct forces in Porter's model, while competitive uncertainty encompasses potential entrants, 
industry competitors, and substitutes. These factors affect both returns and risk in an industry. Porter (1985) demonstrates the use of the five forces framework for assessing industry uncertainties.

In addition to industry effects, segmentation of markets by country divisions should affect input, competitive, and product demand uncertainties. Variations in these uncertainties across countries result from differing national resource endowments and government policies. Government policy decisions regarding, for example, the exchange rate and availability of foreign exchange to the private sector, business regulation, corporate taxes, tariffs and subsidies, and restrictions on the entry of new firms and technologies contribute to shaping the competitive forces within an industry. Policy differences across countries contribute to industry segmentation. Managerial perceptions of input, competitive, and demand uncertainties should differ due to variations in the nature of industry forces across countries. The impact of country differences is evident, for example, when the uncertainty regarding government policy toward business (e.g., taxation or regulation) results in uncertainty regarding new entrants or strategic moves by firms in an industry. Uncertain foreign exchange rates can create uncertainty regarding the cost and availability of an industry's imported inputs and the value of exports. Based on such observations, Austin (1990) refers to governments as "mega-forces" shaping industry structure and dynamics in developing countries.

The preceding discussion can be summarized in the following hypothesis:

H2: Input, product market demand, and competitive uncertaint1es differ across both countries and industries.

Two alternative hypotheses deserve consideration. First, the above discussion suggests that country-industry interactions may explain differences in input, competitive, and demand uncertainties. While testing for interaction effects could provide some interesting empirical results, the restricted size of the available data set only allowed testing for country and industry main effects. 
A second alternative hypothesis is that uncertainty perceptions are particular to firms and, as such, country and industry factors do not provide a basis for explaining uncertainty perceptions. Support for firm-specific uncertainties can be found in Yasai-Ardekani's (1986) conceptual model in which managers' environmental perceptions vary with individual, organizational, and industry characteristics. Similarly, Ting (1988) and Lessard (1988) claim many risks are investment-specific microrisks. To the extent that organizational factors determine uncertainty perceptions, perceptions of environmental uncertainties are firm-specific and do not vary systematically across industries nor countries.

\section{MEASURING MANAGERIAI UNCERTAINTIES}

\section{Background}

A major obstacle to empirical research on perceived environmental uncertainties is the lack of well established measurement instruments. Existing measures from organization theory suffer from conceptual problems and inadequate reliability and validity. Downey, Hellriegel, and slocum point out, "For the most part, contingency researchers have not examined rigorously the conceptual and methodological adequacy of their own uncertainty instruments. The primary means for validating uncertainty instruments has been face validity and the researchers' a priori expectations" (1975b: 613). Their statement is still true today.

In the strategic management and organization literature, the two most widely applied approaches to measuring perceived uncertainty are those of Lawrence and Lorsch (1967) and Duncan (1972). The Lawrence and Lorsch uncertainty measures are not very useful for research on environmental uncertainties because their indicators encompass primarily intraorganizational rather than external environmental uncertainties. The three main areas covered in the Lawrence and Lorsch instrument are the clarity of job requirements, the degree of difficulty in accomplishing assigned jobs, and the length of time required to receive performance feedback. A further difficulty was pointed out by Tosi, Aldag, and Storey (1973), and Downey, Hellriegel, and Slocum (1975b) who found that the Lawrence and Lorsch uncertainty subscales 
did not demonstrate adequate reliability.

Downey, Hellriegel, and Slocum (1975b) criticized Duncan's (1972)

measure of perceived environmental uncertainty for deficiencies in scale construction and low scale reliability. An additional problem with the Duncan measure was the absence of significant positive relations between Duncan's perceptual measures and the four criterion measures of environmental uncertainty used by Downey, Hellriegel, and Slocum (1975b) .

While these problems suggest a need for some modification of the Duncan (1972) measures, the primary shortcoming of Duncan's approach for strategy and international business research is the aggregation of uncertainties regarding a diverse range of environmental components into a single uncertainty measure. Duncan's perceived environmental uncertainty instrument lists five components of the external environment: customers, suppliers, competitors, sociopolitical, and technological. Rather than keeping these measures separate. Duncan pooled respondents' scores on these five dimensions to obtain simplecomplex and static-dynamic environmental indices. Duncan's measure of perceived uncertainty reduced multiple items to a single scale. Bourgeois (1985) used a similar procedure to measure perceived uncertainty. The pooling of perceived uncertainty scores on multiple items into a single scale presumes environmental uncertainty is a single, unidimensional construct.

By contrast, Tosi and Slocum (1984) argued that uncertainty is most appropriately measured in relation to specific environmental components. They identified the following uncertain environmental sectors for business organizations: customers, capital sources, raw product supplies, and technology and science.

Hrebiniak and Snow (1980) offered evidence that managers distinguish between the levels of uncertainty associated with distinct environmental components. As part of that study, managers ranked 19 items about their industry which loaded on five factors reflecting the degree of predictability of financial/capital markets, government regulation and intervention, the actions of competitors, suppliers actions, and general conditions. Unfortunately, Hrebiniak and Snow simply describe these results without presenting the actual factor loading pattern. The usefulness of the study for 
future research is also limited because the authors do not list the 19 questionnaire items. Nevertheless, their study provides preliminary evidence from four industries that managers perceive their environments to consist of distinct uncertain components.

The uncertainty measurement instrument developed in this research resembles most closely that of Miles and Snow (1978). Based on earlier work by Dill (1958), Katz and Kahn (1966), Lawrence and Lorsch (1967), and Thompson (1967), Miles and Snow's measurement instrument included 25 items falling into six broad categories: (1) suppliers of raw materials and components, (2) competitors' actions, (3) customers, (4) financial/capital market, (5) government regulatory agencies, and $(6)$ actions of labor unions. Respondents classified each item on a seven point scale ranging from "predictable" to "unpredictable." Miles and snow reported averages from each of the six scales and an aggregate average combining the six scales for two industries-electronics $(n=22)$ and food-processing $(n=27)$. They did not, however, report subscores for each of the six uncertainty categories nor did they examine the measurement properties of the perceived environmental uncertainty (PEU) instrument itself.

Jackson, Schuler, and Vredenburgh (1987) adopted the Miles and snow (1978) classification of uncertain environmental components. They note that economic, political, sociocultural events, and technology may be sources of uncertainty. Hitt, Ireland, and Palia (1982) used the Miles and Snow (1978) PEU measure. As with Miles and Snow's original PEU measure, their analyses were based solely on the aggregate PEU scores derived from the summation of the six scale averages.

The perceived environmental uncertainty measurement instrument developed in this research departs from those used in previous studies by disaggregating managers' uncertainty perceptions regarding distinct elements of their organizations' environments. The disaggregation of uncertainty perceptions responds to criticisms of the conceptual and operational approaches to uncertainty found in previous research. Milliken contends:

...aggregating uncertainty scores into a global measure of perceived environmental uncertainty, as has past research (e.g.. Downey et al., 1977; Duncan, 1972), may mask significant 
differences between types of uncertainty. Such a masking of differences may be of particular concern when the goal of research is to understand the process of environmental interpretation

(1990: 58).

Leblebici and Salancik offer a similar critique:

Although it is clear that diversity and volatility are related to organizational functioning, investigators in this area have failed to appreciate the need to specify particular conditions of uncertainty. Studies in this area have been more global, designed to characterize an organizational environment abstractly, removed from its particulars. Such underspecification has been the basis of the chief criticism of such studies (1981: 579).

Drawing from international business, strategy, and related research, Miller (1992) developed a typology for decomposing the environment into distinct elements when measuring uncertainty perceptions. In keeping with the uncertainty categories presented in that article, the questionnaire developed for this study includes two general environmental uncertainty categories-political and government policy, and macroeconomic. Corresponding to the industry level, the survey includes items related to input, product market, competitive, and technological uncertainties. Managers were asked to indicate their evaluations of the predictability of each of these environmental components. Rankings were recorded on Likert-type scales ranging from 1 leasy to predict) to 7 (not predictable). The appendix contains the specific items included in the PEU instrument.'

\section{Uncertainty Item Reliability}

Previous management research indicates uncertainty perceptions may vary across individuals within a given firm. Several studies (Anderson \&. Paine, 1975; Downey, Hellriegel, \& Slocum, 1975a, 1975b; Downey \& Slocum, 1975; Duncan, 1972; Jackson, Schuler, \& Vredenburgh, 1987; Lorenzi, 1980; McCaskey, 1976) contend individual factors such as tolerance for ambiguity, cognitive complexity, and internal versus external locus of control affect managers' perceptions of environmental uncertainty. Lorenzi, Sims, and Slocum (1981) showed that perceived environmental uncertainty results from a combination of environmental stimuli, individual characteristics, and the degree of taskrelated specificity of the PEU measure. General measures of environmental uncertainty were found to be strongly influenced by individual 
characteristics. When the measures were more specific or task-related, the objective level of environmental stimulus was found to be much more significant than individual characteristics in explaining uncertainty perceptions.

The influence of individual characteristics on uncertainty perceptions is consistent with earlier work by Dearborn and Simon (1958) indicating executives' functional areas within their organizations affect environmental perceptions. Similarly, Tosi, Aldag, and storey (1973), in attempting to explain the lack of significant relations between the Lawrence and Lorsch (1967) subjective uncertainty scales and objective measures of uncertainty, speculated that managers may not perceive uncertainty outside their functional areas. Bourgeois (1985) argued that since top management team members attend to different functional area responsibilities, their attention is on different segments of the environment and, as such, they experience different levels of perceived uncertainty. A study by Ireland, et al. (1987) found support for differences in environmental uncertainty perceptions across managerial levels. That study, however, found significant differences in uncertainty perceptions between top and lower managerial levels in the organization but not between top and middle managers.

If uncertainty perceptions are not shared by top-level managers within firms, we would question previous research seeking to explain organizational strategy, structure, and processes as responses to uncertainty. It is much less likely that uncertainty perceptions impact organizational strategic decisions if they are idiosyncratic to individuals than if they are shared by members of the top management team. If, however, several managers indicate similar uncertainty perceptions, this would provide evidence for the reliability of the PEU measures and the legitimacy of treating uncertainties as explanatory variables in organizational research. The first step in the empirical analysis involved determining which of the indicators demonstrate adequate reliability across top management personnel. 


\section{METHODOLOGY AND RESULTS}

\section{Description of the sample}

This study departed from previous uncertainty research by creating and analyzing an international data set rather than focusing solely on managers in a single country. Managers from six Latin American countries--Costa Rica, El Salvador, Guatemala, Honduras, Nicaragua, and Panama--provided data. The common business language (Spanish) shared by the sample countries eliminated the possibility of language effects accounting for differences in the survey responses across countries.

All of the managers were selected from the top management team in each organization. Thus, the perceptions represent those of the dominant coalition who directly affect organizational strategic decisions. While all were top management team members, their backgrounds included work in a wide variety of functional areas.

Previous research cautions against casual use of single key informant responses to represent organizational level constructs (Phillips, 1981; Seidler, 1974). In order to explicitly investigate the convergent validity of responses across informants within firms, questionnaire response were solicited from three managers per firm. For each firm in the sample, responses to the questionnaire items were solicited in an interview with one of the members of the top management team at their place of work. When possible, an additional one or two managers from each firm completed a questionnaire containing the same PEU items. No interview was conducted with the second and third questionnaire respondents. Since not all firms agreed to have additional managers participate in the study, the number of respondents per firm varied from one to three. ${ }^{2}$ A total of 497 managers from 211 firms provided usable responses. Table 1 shows the distribution of the sample firms by International Standard Industrial classification (ISIC) code and country. Tables 2 and 3 indicate the size of the firms, as measured by annual sales, and the percent of domestic ownership. Of the 211 firms, 157 had majority local ownership, while 31 firms were wholly-owned foreign subsidiaries. 
Item Rellabilitias

This study used an analysis of variance method to obtain item reliability estimates (Ebel, 1951). The model used was a simple one-way random effects ANOVA model (Neter, Wasserman, \& Kutner, 1985). An F test indicates the extent to which firm effects account for differences in managerial uncertainty perceptions. ${ }^{3}$ If firm effects are not significant, the indicator demonstrates poor reliability. The F test uses a ratio of the firm mean square to the error mean square. The ANOVA model error term encompasses both the variations due to differing data collection methods (interviews and written questionnaires) and individual managerial characteristics. The .05 level was adopted as the decision criterion for determining whether firm effects were significant in explaining differences in managers' reported uncertainty scores.

Since the number of respondents varied from one to three in each firm, the sample was unbalanced. Of the 211 firms in the sample, 131 provided responses from three managers, 24 provided two responses, and 56 had a single respondent." Given this unbalanced design, the appropriate analysis of variance methodology was the regression approach to ANOVA (Neter, Wasserman, \& Kutner, 1985). This method was implemented using the SAS (1985) generalized least squares procedure. Tables $4 \mathrm{~A}$ and $4 \mathrm{~B}$ report the $\mathrm{F}$ statistics and sample sizes for each ANOVA. Respondents' omitted items caused differences in the sample sizes from one item to another.



Put Tables $4 \mathrm{~A}$ and $4 \mathrm{~B}$ here

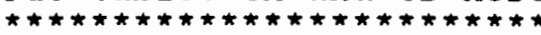

Most of the perceived uncertainty items demonstrate adequate reliability. Eight of the ten political and government policy PEU indicators and three of the four macroeconomic PEU indicators show firm effects with $p$ values less than the .05 cutoff. Five of the seven indicators of the uncertainty of inputs and services used by the firm have adequate reliability. Only the most general of the four product demand indicators demonstrates significant $F$ test results. Four of the six competitive uncertainty indicators satisfy the .05 criterion.

None of the four technological uncertainty variables met the .05 
criterion. As such, the technological uncertainty category was dropped entirely from the subsequent analyses. Although management theory suggests linkages between technological uncertainty and firm strategic decisions, the empirical results cast doubts on the extent to which technological uncertainty perceptions generalize across top managers in the same firm. Although individual characteristics--such as functional area backgrounds--may account for the perceptual differences, such an analysis is beyond the scope of this paper.

For each of the uncertainty measurement items with $F$ test ratios significant at the .05 level, the responses of managers within each firm were averaged to obtain a mean response. The analyses reported in the remainder of the paper used the mean scores for each companies' top management. Items not satisfying the .05 criterion were not included in the analyses reported in the next section.

\section{Country and Industry Effects on Perceived Uncertainties}

The tests for differences in the various PEUs across countries and industries involved a two-factor analysis of variance model. All of the PEUs with adequate reliabilities in Tables $4 \mathrm{~A}$ and $4 \mathrm{~B}$ were included in the analyses. Each firm was classified into one of six countries and one of the eight single-digit International standard Industrial Classification (ISIC) codes represented in the sample (see Table 1). As was the case with the ANOVA reliability tests reported above, the sample sizes within each factor subgroup were unequal, indicating the regression approach to ANOVA was appropriate.

Table 5 reports the test statistics for industry and country effects and the sample sizes for each ANOVA. F statistics were calculated treating the effect to be tested as the last variable added. This procedure has the attribute that the tests are invariant to the ordering of effects in the regression model.

Put Table 5 here

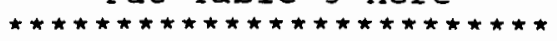

The resuits indicate support for the hypothesis (H1) that managers' political, government policy, and macroeconomic uncertainty perceptions differ 
significantly across countries but not across industries. All of the political, policy, and macroeconomic uncertainty variables differ significantly across countries. The finding that the perceived uncertainty of armed conflict differs across industry groups was not anticipated. This result may be due to differences in vulnerability to armed conflict across industries depending on the nature of the industries' activities.

The two-factor ANOVA results for the input, demand, and competitive uncertainties are more difficult to interpret than those for political, policy, and macroeconomic uncertainties. As stated in $\mathrm{H} 2$ above, the hypothesis was that both country and industry effects would be significant in explaining differences in these PEUs. In fact, only three of the input uncertainties show country effects significant at the .05 level. None of the industry effects are significant. Thus, neither country nor industry effects provide much explanatory power across most of the input, market demand, and competitive uncertainties.

There are two related explanations for this finding. One possibility is that defining industries at the single-digit ISIC code places firms in industry categories that are too broad to capture industry effects. Alternatively, following Ting (1988) and Lessard (1988), it may be the case that any industry grouping, no matter how refined, would fail to provide significant explanatory power because the uncertainties are unique to the environmental circumstances and distinctive characteristics of individual firms. That is, perceived input, competitive, and demand uncertainties may be so idiosyncratic that no generalizations can be made to other firms.

In order to evaluate the possibility that narrower industry classifications could result in significant industry effects consistent with hypothesis two, the firms in the largest single-digit IsIC category in the sample, manufacturing (ISIC 3000), were reclassified into two-digit ISIC categories. Of the 84 manufacturing firms, 31 firms were food, beverage, and tobacco manufacturers (ISIC 31 ) and 29 were manufacturers of chemicals and chemical, rubber, and plastic products (ISIC 35). The remaining 24 firms were scattered among the other seven two-digit manufacturing categories. ANOVA results using the six country categories and two two-digit ISIC categories $(31$ 
and 35$)$ were consistent with those reported in Table 5. Two-digit industry effects were generally not significant at the .05 level. The one exception was uncertainty regarding changes in competitors' strategies which showed a significant $(p<.01)$ two-digit industry effect.

These results provide further evidence that perceptions of input, product demand, and competitive uncertainties are idiosyncratic to firms. The results are consistent with Ting (1988) and Lessard's (1988) contention that many risks are firm or project-specific. One exception, uncertainty regarding competitors' changes in strategy, appears to generalize across firms at the two-digit industry level.

\section{DISCUSSION}

\section{Measurement Instrument}

The measurement instrument developed in this research proved to have adequate reliability across managers within firms for most of the perceived uncertainty items. While previous research indicates that individual characteristics may influence uncertainty perceptions, the reliabilities reported in Tables $4 \mathrm{~A}$ and $4 \mathrm{~B}$ demonstrate agreement among top managers within firms as to the uncertainty associated with a variety of environmental components. This finding is important since it allows researchers to treat the uncertainty items with adequate reliability as measuring shared perceptions across top management team members rather than perceptions idiosyncratic to individual managers. Top management's shared uncertainty perceptions are more likely to influence organizational strategic decisions than individual-specific perceptions.

of the thirty-five uncertainty indicators, twenty-one had $F$ test ratios significant at the .05 level. While managers within firms generally agreed on the uncertainty of political, government policy, macroeconomic, input, and competitive items, there was much less agreement on the product market and technology uncertainty items.

The findings indicate that managers are capable of differentiating the uncertainties associated with distinct environmental components. This conclusion raises serious doubts about the adequacy of organization theorists' 
conceptualization of uncertainty as a single unidimensional construct. It would be surprising if the different types of managerial uncertainties did not have very different implications for firm strategic decisions. For example, corporate responses to political uncertainty should be quite different from responses to competitive uncertainty. While this proposition has face validity, such distinctions between types of uncertainties are largely absent from organization theory research on uncertainty responses. Future research on the relations between the various uncertainties and organization strategy, structure, and process may provide insights that previous management research treating uncertainty as a single construct could not.

The finding that managers distinguish a variety of environmental uncertainties also challenges the tendency in strategy and international business research to treat particular organizational uncertainties in isolation from others. The approach to uncertainty in the strategy field provides an important complement to existing international risk management research focusing largely on political, policy, and macroeconomic uncertainties. The use of financial or strategic maneuvers to hedge particular corporate risk exposures may fail to take into consideration the interrelationships and tradeoffs between exposures to various uncertain environmental contingencies. Optimal risk management practices involve simultaneous consideration of the full spectrum of corporate exposures to environmental uncertainties (Miller, 1992; Oxelheim \& Wihlborg, 1987; Shapiro \& Titman, 1986).

One limitation of the PEU instrument is its inclusion of a few items that may not be particularly relevant to managers outside the region studied. For example, the uncertainties of armed conflict and the results of economic restructuring may not enter into managerial considerations in many developed countries. In the future, researchers may want to adapt the particular items incorporated in the PEU instrument to reflect the environmental components relevant to managers in other countries or types of organizations. The typology of uncertainties offered in Miller (1992) provides a basis for generating alternative items. The measurement properties of additional or alternative items to the scales should be carefully examined. While the 
empirical findings reported in this paper indicate managers' rankings of the predictability of environmental components on Likert-type scales have some desirable measurement properties, future research could examine the reliability of these measures using samples from other countries.

\section{Country and Industry Effects on PEUs}

The study found systematic differences in political, policy, and macroeconomic uncertainties across countries. This was expected. While international risk management research has long advocated country risk assessments focusing on political, policy, and macroeconomic risks, this study contributes empirical evidence indicating managers' perceptions of these uncertainties differ across countries.

Neither industry nor country accounted for differences in most input, competitive, and market demand uncertainties. As noted in the discussion of the ANOVA results, the relevance of industry cannot be entirely discounted until further research is conducted using narrower industry classifications. Nevertheless, the results indicate that while managers may receive useful insights into political, policy, and macroeconomic uncertainties by conducting country-level evaluations, such evaluations offer little information regarding a number of uncertain contingencies vital to the success of an investment project.

$$
\text { In assessing foreign investment risks, the findings of this study }
$$
suggest that managers will gain insights by considering the general environmental (macroeconomic, political, and government policy) context of the host country, but country-level assessments need to be supplemented with firmspecific, or even investment-specific, risk considerations. For general environmental components, the uncertainty perceptions of managers within a country appear to be widely shared across industries. Nevertheless, a comprehensive assessment of the risk exposures associated with foreign investment requires consideration of input, product market demand, and competitive uncertainties. Risk exposures to this latter set of environmental contingencies may be firm or investment-specific and as such, merit analyses supplemental to country-level assessments. 



\section{ENDNOTES}

1. The study used a Spanish version of the survey instrument prepared by the author and three other bilingual individuals. This committee approach to translation is one of the methods recommended by Brislin (1980). Appendix A is a back translation written from the Spanish questionnaire.

2.An implication of the sampling procedure is that some of the reliability measures most commonly used in management research, such as cronbach's (1951) alpha or other inter-rater measures, are not appropriate here. Such measures require that there be a basis for classifying the respondents from each firm into distinct categories. Functional area backgrounds and position are two examples of categories used in multiple respondent organizational research. In the case of Cronbach's alpha, categorization of respondents is necessary in order to generate a unique correlation matrix and only those firms with data from all three respondents could be included in the reliability estimate. For this data set, a classification of managers by method (interview for the first manager versus questionnaire for managers two and three) would differentiate one of the three managers. No differentiation could be made, however, between the two questionnaire respondents.

The ANOVA approach to reliability estimation described in the next section has the advantages that (1) it does not require categorization of respondents and (2) it uses the data from all firms in the sample rather than solely those with the full set of three respondents.

3.For a discussion of the interpretation of ANOVA $F$ ratios as measures of reliability see Dansereau, Alutto, and Yammarino (1984).

4. As explained earlier, the $F$ test uses a ratio of the firm mean square to the error mean square. Inclusion of a single-respondent firm does not increase the error sum of squares nor its associated degrees of freedom. Hence, inclusion of the single-manager firms does not change the error mean square. Nevertheless, the single-manager firms do contribute additional information 
about the firm mean square. While each single-manager firm increases the total between firm variance, each also adds a degree of freedom to the denominator when calculating the firm mean square. Hence, inclusion of the single-manager firms in the ANOVA reliability $F$ tests provides additional information but does not bias the $F$ test results.

ANOVA $F$ test results generated using only the 155 firms with multiple respondents were broadly consistent with the reported results for the full 211 firms sample. All of the significant ( $p<.05$ ) perceived uncertainty $F$ tests reported in tables $4 \mathrm{~A}$ and $4 \mathrm{~B}$ were also significant using the subsample of 155 firms. The subsample tests also indicated three other PEU indicators had significant reliability based on their F statistics (interest rate uncertainty, $p=.020$, uncertainty of client preferences, $p=.041$, and uncertainty of product quality changes, $p=.038$ ). Hence, the results reported in tables $4 \mathrm{~A}$ and $4 \mathrm{~B}$ are more conservative than the results obtained when single-respondent firms are removed from the analysis. 


\section{RERERENCES}

Anderson, C. R. \& Paine, F. T. 1975. Managerial perceptions and strategic behavior. Academy of Management Journal, 18: 811-823.

Austin, J. E. 1990. Managing in developing countries. New York: Free Press.

Bourgeois, L. J., III. 1985. Strategic goals, perceived environmental uncertainty, and economic performance in volatile environments. Academv of Management Journal. 28: 548-573.

Brislin, R. W. 1980. Translation and content analysis of oral and written materials. In Triandis, H. C. \& Berry, J. W. (Eds.) Handbook of cross-cultural psychology: Methodolooy, Vol. 2: 389-444. Boston, Massachusetts: Allyn and Bacon.

Cronbach, L. J. 1951. Coefficient alpha and the internal structure of tests. Psychometrika, 16: 297-334.

Dansereau, Fred, Joseph A. Alutto, \& Francis J. Yammarino. 1984. Theory testing in organizational behavior: The variant approach. Englewood Cliffs, New Jersey: Prentice-Hall.

Dearborn, D. C. \& Simon, H. A. 1958. Selective perception: A note on departmental identification of executives. Sociometry, $21: 140-144$.

Dill, W. R. 1958. Environment as an influence on managerial autonomy. Administrative Science Quarterly, 2: 409-443.

Downey, H. K.. Hellriegel, D. \& Slocum, Jr., J.W. 1975a. The effects of individual differences on managers' perceptions of environmental uncertainty. Academy of Management Proceedings: 200-202.

Downey, H. K., Hellriege1, D. \& Slocum, Jr., J. W. 1975b. Environmental uncertainty: The construct and its application. Administrative Science Quarterly, 20:613-629.

Downey, H. K., Hellriegel, D., \& Slocum, Jr., J. W. 1977. Individual characteristics as sources of perceived uncertainty variability. Human Relations, $30: 161-174$.

Downey, H. K. \& Slocum, J. W. 1975. Uncertainty measures, research, and sources of variation. Academy of Manaqement Journal, 18: 562-578.

Duncan, R. B. 1972. Characteristics of organizational environments and perceived environmental uncertainty. Administrative Science Quarterly, 17: 313-327.

Ebel, R. L. 1951. Estimation of the reliability of ratings. Psychometrika, 16: $407-424$.

Hitt, M. A., Ireland, R. D. \& Palia, K. A. 1982. Industrial firms' grand strategy and functional importance: Moderating effects of technology and uncertainty. Academy of Management Journal, 25: 265-298.

Hofstede, G. 1980 Culture's Consequences. Beverly Hills, California: Sage.

Hrebiniak, L. G. \& snow, C. C. 1980. Industry differences in environmental uncertainty and organizational characteristics related to uncertainty. Academv of Manadement Journal, 23:750-759. 
Ireland, R. D., Hitt, M. A., Bettis, R. A., \& Auld De Porras, D. 1987. Strategy formulation processes: Differences in perceptions of strength and weaknesses indicators and environmental uncertainty by managerial level. Strateqic Manaqement Journal, 8: 469-485.

Jackson, S. E.. Schuler, R. S., \& Vredenburgh, D. J. 1987. Managing stress in turbulent times. In Riley, A. W. \& Zaccaro, S. J. (Eds.) Occupational stress and organizational effectiveness: 141-166. New York: Praeger.

Katz, D. \& Kahn, R. L. 1978. The social psvcholoay of orqanizations (2nd ed.). New York: John Wiley.

Kobrin, S. 1982. Manaqing political risk assessment. Berkeley: University of California Press.

Lawrence, P. R. \& Lorsch, J. W. 1967 . Orqanization and environment : Managing differentiation and integration. Boston: Harvard Business School Press.

Leblebici, H. \& Salancik, G. 1981. Effects of environmental uncertainty on information and decision processes in banks. Administrative science Quarterly, 26 : $578-596$.

Lessard, D. R. 1988. Country risk and the structure of international financial intermediation. In Stone, C. C. (Ed.) Financial risk: Theorv, evidence and implications: 197-233. Boston, Massachusetts: Kluwer Academic Publishers.

Lorenzi, P. 1980. Applied behavior under uncertainty. In Fiddle, S. (Ed.) Uncertainty: Behavioral and social dimensions: 284-304. New York: Praeger.

Lorenzi, P., Sims, H. P., Jr., \& Slocum, J. W., Jr. 1981. Perceived environmental uncertainty: An individual or environmental attribute? Journal of Management, $7(2): 27-41$.

McCaskey, M. B. 1976. Tolerance for ambiguity and the perception of environmental uncertainty in organizational design. In Kilmann, $R$. H., Pondy, L. R., \& Slevin, D. P. (Eds.) The management of orqanization desion: Research and methodolocy, Vol. 2: 59-85. New York: Elsevier-North Holland.

Miles, R. E. \& Snow, C. C. 1978. Organizational strategy, structure, and process. New York: McGraw-Hill.

Miller, K. D. 1992. A framework for integrated risk management in international business. Journal of International Business Studies, 23 (2): forthcoming.

Milliken, F. J. 1990. Perceiving and interpreting environmental change: An examination of college administrators' interpretation of changing demographics. Academv of Management Journal. 33: 42-63.

Neter, J., Wasserman, W., \& Kutner, M. H. 1985. Applied linear statistical models (2nd ed.). Homewood, Illinois: Irwin.

Oxelheim, Lars \& Clas G. Wihlborg. 1987 Macroeconomic uncertainty: International risks and opportunities for the corporation. New York: John Wiley \& Sons.

Phillips, Lynn W. 1981. Assessing measurement error in key informant reports: A methodological note on organizational analysis in marketing. Journal of Marketing Research, 18: 395-415.

Porter, Michael E. 1980. Competitive strateoy. New York: Free Press. 
Porter, Michael E. 1985. Competitive advantage. New York: Free Press.

Porter, Michael E. 1990. The competitive advantage of nations. New York: Free Press.

Robock, Stefan H. 1971. Political risk: Identification and assessment. Columbia Journal of World Business, July-August : 6-20.

SAS. 1985. SAS user's quide: Statistics (Version 5 ed.). Cary, N.C.: SAS Institute Inc.

Seidler, John. 1974. On using informants: A technique for collecting quantitative data and controlling measurement error in organization analysis. American Sociological Review, 39: 816-831.

Shapiro, Alan C. \& Sheridan Titman. 1986. An integrated approach to corporate risk management. In Joel M. Stern \& Donald $\mathrm{H}$. Chew (eds.) The revolution in corporate finance. Boston: Blackwell.

Shubik, M. 1983. Political risk: Analysis, process, and purpose. In R. J. Herring (Ed.) Manading international risk: 109-138. New York: Cambridge University Press.

Simon, Jeffrey D. 1982. Political risk assessment: Past trends and future prospects. Columbia Journal of World Business, Fall: 62-71.

Thompson, J. D. 1967. Organizations in action. New York: McGraw-Hill.

Ting, W. 1988. Multinational risk assessment and manaqement. Westport, Connecticut: Greenwood Press.

Tosi, H., Aldag, R., \& Storey, R. 1973. On the measurement of the environment: An assessment of the Lawrence and Lorsch environmental uncertainty subscale. Administrative Science Quarterlv, 18: 27-36.

Tosi, Jr., H. L. \& Slocum, Jr., J. W. 1984. Contingency theory: Some suggested directions. Journal of Management, $10: 9-26$.

Tversky, A. \& Kahneman, D. 1973. Availability: A heuristic for judging frequency and probability. Cognitive Psvcholoav, 5: 207-232.

United Nations. 1971. Indexes to the international standard industrial classification of ali economic activities, Series M, No. 4, Rev. 2, Add. 1. New York: United Nations.

Yasai-Ardekani, M. 1986. Structural adaptations to environments. Academv of Management Review, 11: 9-21. 


\section{APPENDIX}

In this section, we would like you to describe the environment in which your company operates. In the primary industry and country where you work, evaluate the aspects of your environment. Indicate if the factors are easy or difficult to predict.

1 = Easy to predict, 7 = Unpredictable.

1. Government and policies

Predictable Unpredictable

a. Ability of the party in power to maintain control of the government.

b. Threat of armed conflict.

c. Tax policies.

d. Monetary policy.

e. Prices controlled by the government.

f. National laws affecting international business.

g. Legal regulations affecting the business sector.

h. Tariffs on imported goods.

i. Enforcement of existing laws.

j. Public service provision.

$\begin{array}{lllllll}1 & 2 & 3 & 4 & 5 & 6 & 7 \\ 1 & 2 & 3 & 4 & 5 & 6 & 7 \\ 1 & 2 & 3 & 4 & 5 & 6 & 7 \\ 1 & 2 & 3 & 4 & 5 & 6 & 7 \\ 1 & 2 & 3 & 4 & 5 & 6 & 7 \\ 1 & 2 & 3 & 4 & 5 & 6 & 7 \\ 1 & 2 & 3 & 4 & 5 & 6 & 7 \\ 1 & 2 & 3 & 4 & 5 & 6 & 7 \\ 1 & 2 & 3 & 4 & 5 & 6 & 7 \\ 1 & 2 & 3 & 4 & 5 & 6 & 7\end{array}$

2. Economy

a. Inflation rate.

b. Exchange rate with dollar.

c. Interest rate.

d. Results of economic restructuring.

$\begin{array}{lllllll}1 & 2 & 3 & 4 & 5 & 6 & 7 \\ 1 & 2 & 3 & 4 & 5 & 6 & 7 \\ 1 & 2 & 3 & 4 & 5 & 6 & 7 \\ 1 & 2 & 3 & 4 & 5 & 6 & 7\end{array}$

3. Resources and services used by your company.

a. Availability of trained labor.

b. Labor and union problems.

c. Quality of inputs, raw materials, and components.

d. Availability of inputs, raw materials, and components.

e. Prices of inputs, raw materials, and components.

f. Transportation system within the country.

g. Transportation system to foreign countries.

$\begin{array}{lllllll}1 & 2 & 3 & 4 & 5 & 6 & 7 \\ 1 & 2 & 3 & 4 & 5 & 6 & 7 \\ 1 & 2 & 3 & 4 & 5 & 6 & 7 \\ 1 & 2 & 3 & 4 & 5 & 6 & 7 \\ 1 & 2 & 3 & 4 & 5 & 6 & 7 \\ 1 & 2 & 3 & 4 & 5 & 6 & 7 \\ 1 & 2 & 3 & 4 & 5 & 6 & 7\end{array}$

